\title{
Evaluation of Anti-oxidant Activity and cytotoxicity of Strobilanthes cuspidata (Benth.) T. Anderson
}

\author{
Sincy Joseph, Lekha Kumar, V Narmatha Bai \\ Assistant Professor in Botany, Nirmala College for Women, India \\ Email:- tjsincy@gmail.com
}

\begin{abstract}
Strobilanthes cuspidata (Benth.) Anderson (Acanthaceae) are used by the tribal people of Nilgiri hills for joint pain and inflammation. A detailed study on the natural products present in endemic medicinal plants as well as pharmacological aspects will pave way to discover new drugs. Hence the present study was attempted to assess the biological activities of the crude extracts by antioxidant and cytotoxic assays. The 70\% hydro-ethanolic extract of $S$. cuspidata was prepared to study DPPH radical scavenging activity, hydrogen peroxide scavenging activity, metal chelating activity, total antioxidant activity and in vitro cytotoxicity was assessed in Vero cell lines (African, Green monkey Kidney and Normal). The results showed that the plant extract of $S$. cuspidata possesses antioxidant and free radical scavenging properties. Moreover in vitro cytotoxic activity of the alcoholic leaf extract was assessed in Vero cell lines (African, Green monkey Kidney, normal). The percentage of growth inhibition was calculated using the concentration of the leaf extract to inhibit the cell growth by 50\% (CTC50). The study revealed that the activities observed could be attributed to the presence of some phytochemicals which have been associated with antioxidant and cytotoxic property.
\end{abstract}

Keywords - Strobilanthes cuspidata, antioxidant, cytotoxicity, DPPH, Vero cell lines.

\section{Introduction}

The natural antioxidants are gaining a vast importance due to their fewer side effects. Oxygen free radicals induce damage due to peroxidation to biomembranes and also to DNA, which lead to tissue damage, thus cause occurrence of a number of diseases. Antioxidants may be synthetic or natural. Synthetic antioxidants such as butylated hydroxytoluene (BHT) and butylated hydroxyl anisole (BHA) have recently been reported to be dangerous for human health. Thus the search for effective, non toxic natural compounds with antioxidative activity have been intensified in recent years, (Vivek et al., 2006). An antioxidant when present at low concentrations delays or prevents oxidation of cell content like proteins, lipids, carbohydrates and DNA. Plants can provide drugs to widen the therapeutic arsenal. Traditional systems of medicine have become increasingly important in view of their safety and for this reason, the realization of health hazards and toxicity associated with the indiscriminate use of synthetic drugs and antibiotics and research is carried out in order to determine the toxicity of medicinal plants, (Nguta et al., 2012).

\section{Material and methods}

\section{Preparation of the test solutions}

The plant extract $(210 \mu \mathrm{l})$ was made up to $1 \mathrm{ml}$ using DMSO. The solution was serially diluted to obtain lower concentrations (1000, 500, 250 and 125).

\section{Preparation of standard solution}

Rutin (10 mg) was weighed separately and dissolved in $0.95 \mathrm{ml}$ of DMSO and serially diluted with the same to attain lower concentrations (1000,500, 250 and 125).

a) DPPH radical scavenging activity 
South American Journal of Academic Research

Special Edition May 2016

Scavenging activity on the DPPH free radicals by the test solution was assessed according to Sanchenz-Moreno. (2002). The principle of this assay is based on the scavenging ability of antioxidants towards the stable radical (DPPH). The assay was carried out in a 96 well micro titre plate. To $200 \mu \mathrm{l}$ of DPPH solution $(100 \mu \mathrm{M}), 10 \mu \mathrm{l}$ of each of the test sample were added. The plates were incubated at $37^{\circ} \mathrm{C}$ for 20 minutes and the absorbance of each solution was measured at $490 \mathrm{~nm}$ using ELISA reader. The activity \% DPPH scavenging was calculated according to the following equation:

$\%$ Inhibition $=\left\{\left(A_{B}-A_{A}\right) / A_{B}\right\} \times 100$,

where $A_{B}$ is the absorbance of blank sample and $A_{A}$ the absorption of test sample.

\section{b) Hydrogen Peroxide assay}

The hydrogen peroxide scavenging activity of the test solution was determined by the method of Ruch et al. (1989). The test solution was dissolved in $3.4 \mathrm{ml}$ of $0.1 \mathrm{M}$ phosphate buffer (pH-7.4) and mixed with $600 \mu \mathrm{l}$ of $43 \mu \mathrm{M}$ solution of hydrogen peroxide. $210 \mu \mathrm{l}$ of the solution was pipette onto 96 well micro titre plates. The absorbance was measured at $230 \mathrm{~nm}$ using ELISA reader.

$\%$ Inhibition $=\left\{\left(\mathrm{A}_{\mathrm{B}}-\mathrm{A}_{\mathrm{A}}\right) / \mathrm{A}_{\mathrm{B}}\right\} \times 100$,

Where $A_{B}$ is the absorbance of blank sample and $A_{A}$ the absorption of test sample.

c) Metal chelating activity on ferrous ions

Metal chelating activity was determined according to the method of Decker and Welch (1990). The test solution $(0.5 \mathrm{ml})$ was mixed with $0.05 \mathrm{ml}$ of $2 \mathrm{mM} \mathrm{Fecl}_{2}$ and $0.1 \mathrm{ml}$ of $5 \mathrm{mM}$ ferrozine. The total volume was diluted with $2 \mathrm{mM}$ methanol and shaken vigorously. The solution $(210 \mu \mathrm{l})$ was pipette onto 96 well micro titre plates and kept at room temperature for 10 minutes. The absorbance of the solution was measured at $562 \mathrm{~nm}$ using ELISA reader. The $\%$ of inhibition of ferrozine- $\mathrm{Fe}^{2+}$ complex formation was calculated using the formula:

$\%$ Inhibition $=\left\{\left(A_{B}-A_{A}\right) / A_{B}\right\} \times 100$,

Where $A_{B}$ is the absorbance of blank sample and $A_{A}$ the absorption of test sample.

d) Total antioxidant activity

The total antioxidant capacity was estimated by phosphomolybdenum method (Guddadarangavvanahally et al., 2004; Pongtip Sithisarn et al., 2005). Sulphuric acid (0.6 M) solution, sodium sulphate $(28 \mathrm{mM})$ solution and ammonium molybdenate $(4 \mathrm{mM})$ solution were mixed together and labelled as Total Antioxidant Capacity (TAC reagent). $100 \mu 1$ of the test solution was dissolved in $1 \mathrm{ml}$ of TAC reagent. From this solution $210 \mu \mathrm{l}$ was pipette onto a 96 well micro titre plate. The absorbance was measured at $695 \mathrm{~nm}$ using ELISA reader. Blank was maintained with distilled water replacing the TAC reagent.

$\%$ Inhibition $=\left\{\left(A_{B}-A_{A}\right) / A_{B}\right\} \times 100$, where $A_{B}$ is the absorbance of blank sample and $A_{A}$ the absorption of test sample.

\section{In vitro Cytotoxicity assay}

In vitro cytotoxicity was assessed in Vero cell lines (African, Green monkey Kidney, and Normal). The test solution was dissolved in $1 \mathrm{ml}$ of DMSO and the volume was made up to $10 \mathrm{ml}$ with maintenance medium to obtain a stock solution of $10 \mathrm{mg} / \mathrm{ml}$ concentration, sterilized by filtration and further dilutions were made from the stock. The cytotoxic assays were carried out using $0.1 \mathrm{ml}$ of cell suspension, containing 10,000 cells/well of a 96 well microtitre plate. Fresh medium containing different concentrations of the test solution were added after $24 \mathrm{~h}$ of partial monolayer. Control cells were incubated without test solution and with MEM. The microtitre plates were incubated at $37{ }^{\circ} \mathrm{C}$ in a humidified incubator with 5 percent $\mathrm{CO}_{2}$ for a period of $72 \mathrm{~h}$. Four wells were used for each concentration of the test solution. The morphology of the cells was inspected daily. The cytopathogenic effect (CPE) was scored. The 50 percent cytotoxic concentration $\left(\mathrm{CTC}_{50}\right)$ was determined by the standard MTT assay (Francis and Rita, 1986). After 72 h, $20 \mu 1$ of MTT solution (2 mg/ml in PBS) 
was added to the plates and was incubated for $4 \mathrm{~h}$ at $37{ }^{\circ} \mathrm{C}$. MTT-formazon crystals formed were dissolved in $100 \mu \mathrm{l}$ of iso propanol and optical density was read with a microtitre plate reader (Biorad) at $570 \mathrm{~nm}$.

\section{Results}

The ethanolic extract of Strobilanthes cuspidata was tested for antioxidant activity by several tests, namely DPPH free radical scavenging activity, hydrogen peroxide assay, metal chelating activity on ferrous ions and Total antioxidant activity.

a) DPPH radical scavenging activity

Free radical, 2, 2-diphenyl-1-picrylhydrazine (DPPH) is widely used in testing the ability of compounds to act as free radical scavengers or hydrogen donors and to evaluate antioxidant activity. The radical scavenging activity was expressed as the percentage of reduction of the initial DPPH radical absorbance by the extract. The extract may scavenge DPPH radicals in dose dependent manner with increased activities at higher concentration (Figure-1). The results obtained are listed in Table-14.The inhibitory concentration of the plant extract against the DPPH radicals was calculated as $132 \mu \mathrm{g} / \mathrm{ml}$. The known synthetic antioxidant Rutin showed the $\mathrm{IC}_{50}$ value of $140 \mu \mathrm{g} / \mathrm{ml}$. The results of DPPH scavenging activity assay in this study indicates that the extract were active.

b) Hydrogen Peroxide assay

In hydroxyl radical scavenging method, the extract exhibited antioxidant activity in dose dependant manner and increased with concentration $\mathrm{IC}_{50}$ values of both standard and extract in hydrogen peroxide scavenging assay are shown in Table-15 (Figure-2). The inhibitory concentration of the plant extract against the hydrogen peroxide assay was calculated as $185.4 \mu \mathrm{g} / \mathrm{ml}$. The known synthetic antioxidant rutin showed the $\mathrm{IC}_{50}$ value of $150 \mu \mathrm{g} / \mathrm{ml}$. However the hydrogen peroxide activity of rutin was relatively more pronounced than the extract.

c) Metal chelating activity on Ferrous ions.

The results obtained are listed in Table-16 (Figure-3). The inhibitory concentration of the plant extract against the ferrous ions was calculated as $225 \mu \mathrm{g} / \mathrm{ml}$. The known synthetic antioxidant rutin showed the $\mathrm{IC}_{50}$ value of $165 \mu \mathrm{g} / \mathrm{ml}$. A known synthetic antioxidant rutin showed higher activity than the extract.

d) Total antioxidant activity

The results obtained are presented in Table-17 (Figure-4). The inhibitory concentration of the plant extract against the ferrous ions was calculated as $90 \mu \mathrm{g} / \mathrm{ml}$. The positive control rutin showed the $\mathrm{IC}_{50}$ value of $145 \mu \mathrm{g} / \mathrm{ml}$. The results of total antioxidant activity on ferrous ions indicates that the extract were active.

Table-1 - DPPH radical scavenging activity.

\begin{tabular}{|l|l|l|}
\hline Concentration( $\mathbf{\mu g} / \mathbf{m l})$ & \% inhibition & $\mathbf{I C}_{\mathbf{5 0}}(\boldsymbol{\mu} \mathbf{g} / \mathbf{m l})$ \\
\hline 125 & $47.97 \pm 0.65$ & \multirow{2}{*}{132} \\
\cline { 1 - 2 } 250 & $53.00 \pm 0.29$ & \multirow{2}{*}{132} \\
\hline 500 & $58.09 \pm 0.54$ & \\
\hline 1000 & $67.66 \pm 0.76$ & \\
\hline \multicolumn{2}{|c|}{ Standard (RUTIN) } & 140 \\
\hline
\end{tabular}

Table-2 - Hydrogen Peroxide assay

\begin{tabular}{|c|c|c|}
\hline Concentration $(\mu \mathrm{g} / \mathrm{ml})$ & \% inhibition & $\mathrm{IC}_{50}(\mu \mathrm{g} / \mathrm{ml})$ \\
\hline 125 & $42.73 \pm 0.66$ & \multirow{4}{*}{185.4} \\
\hline 250 & $55.89 \pm 0.39$ & \\
\hline 500 & $65.21 \pm 0.47$ & \\
\hline 1000 & $66.60 \pm 0.72$ & \\
\hline \multicolumn{2}{|c|}{ Standard (RUTIN ) } & 150 \\
\hline
\end{tabular}


South American Journal of Academic Research Special Edition May 2016

Table-3 - Metal chelating activity on Ferrous ions.

\begin{tabular}{|c|c|c|}
\hline Concentration( $\boldsymbol{\mu g} / \mathbf{m l})$ & \% inhibition & IC $\left._{\mathbf{5 0}} \mathbf{(} \boldsymbol{\mu g} / \mathbf{m l}\right)$ \\
\hline 125 & $52.95 \pm 0.35$ & \multirow{2}{*}{225} \\
\hline 250 & $50.24 \pm 0.76$ & \\
\hline 500 & $49.30 \pm 0.50$ & 165 \\
\hline 1000 & $46.67 \pm 0.24$ & \\
\hline \multicolumn{2}{|c|}{ Standard ( RUTIN ) } & \\
\hline
\end{tabular}

Table-4 - Total antioxidant activity

\begin{tabular}{|c|c|c|}
\hline Concentration( $\boldsymbol{\mu g} / \mathbf{m l})$ & \% inhibition & IC $\left._{\mathbf{5 0}} \mathbf{(} \boldsymbol{\mu g} / \mathbf{m l}\right)$ \\
\hline 125 & $44.76 \pm 0.64$ & \multirow{2}{*}{90} \\
\hline 250 & $50.84 \pm 0.40$ & \\
\hline 500 & $58.34 \pm 0.23$ & 145 \\
\hline 1000 & $59.36 \pm 0.24$ & \\
\hline \multicolumn{2}{|c|}{ Standard ( RUTIN ) } & \\
\hline
\end{tabular}

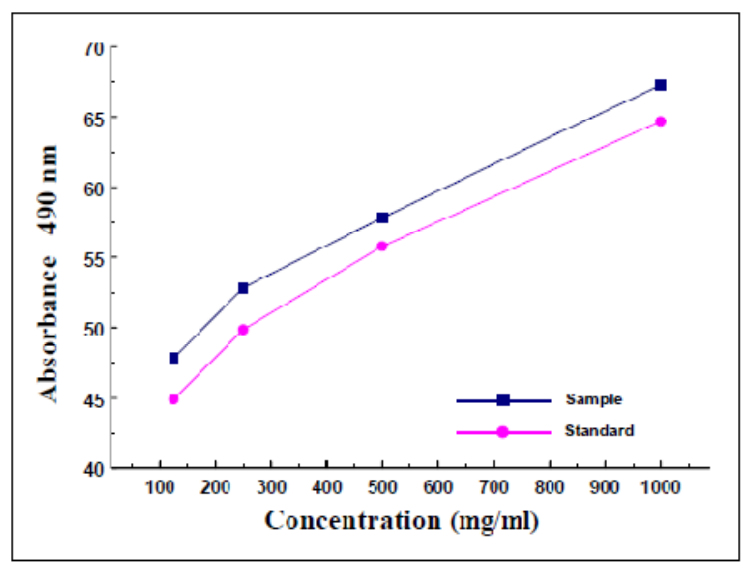

Figure 1- DPPH radical scavenging activity

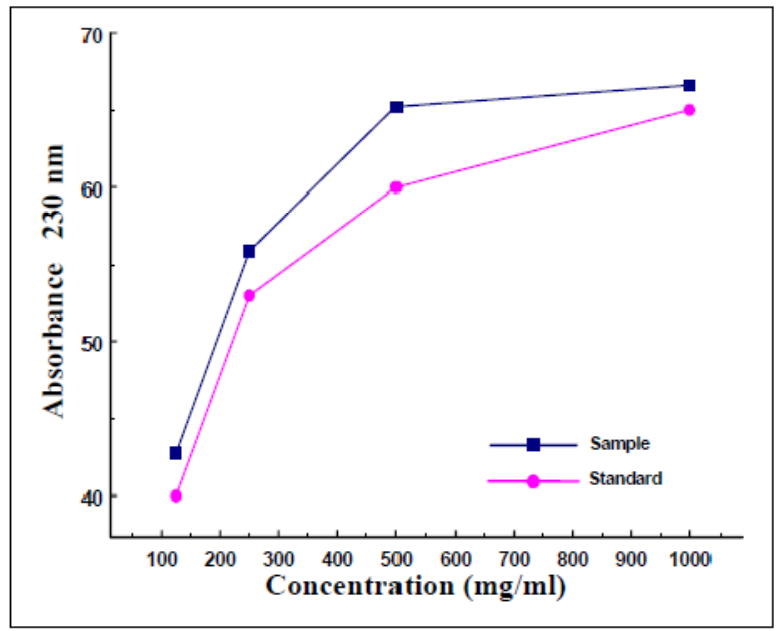

Figure 2- Hydrogen peroxide scavenging activity 


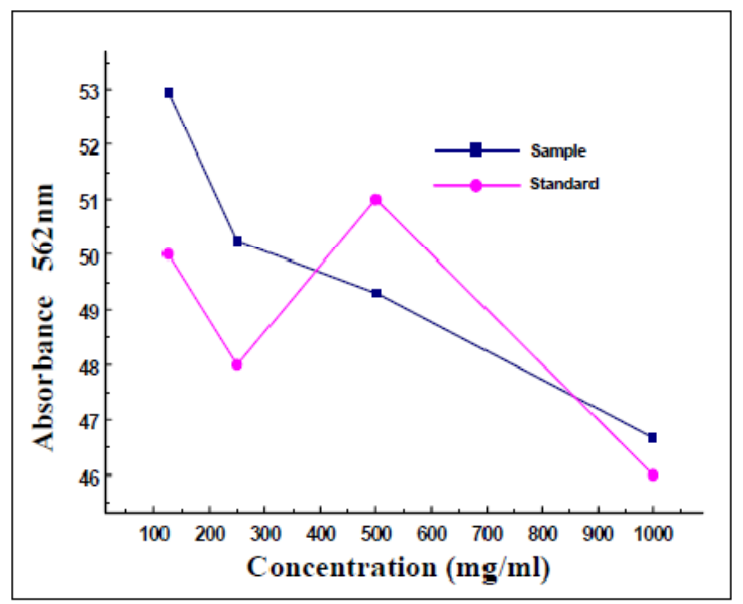

Figure 3- Metal chelating activity on ferrous ions

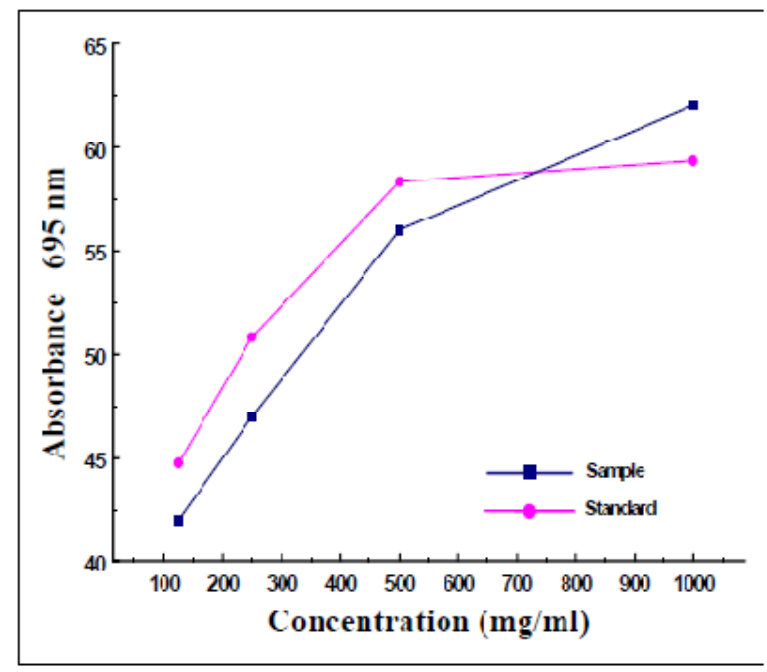

Figure 4-Total antioxidant activity

\section{In vitro Cytotoxicity assay}

The in vitro cytotoxic activity of the alcoholic leaf extract was assessed in Vero cell lines (African, Green monkey Kidney, normal). The $\mathrm{CTC}_{50}$ value (the effective concentration of the sample required to inhibit the cell growth by 50\%) of the extract was calculated from the growth response curve plotted between percentage inhibition and concentration and was found to be $190 \mu \mathrm{g} / \mathrm{ml}$.

\section{Discussion}

Extensive antioxidant studies have been carried out on medicinal plants of Acanthaceae family. Strobilanthes is a wide spread genus with a diversity of ethanobotanical uses. Strobilanthes crispus (Asmah Rahmat, 2006), Strobilanthes asperrimus (Pradeep, 2013), S.ciliatus (Jayaraman, 2014) proved to have high antioxidant activity. The results obtained in the present study indicate that the leaves of $S$. cuspidata are potential source of natural antioxidants and the antioxidant capacities of the alcoholic leaf extracts of $S$. cuspidata was evaluated by four in vitro methods.

The powerful antioxidants including superoxide anions, hydroxyl radicals and hydrogen peroxide are known as free radicals. Free radicals are unguided missiles that bounce around and attack healthy cells, tearing the cell membranes causing genetic damage and mutations. They react with serum lipoprotein (LDL) and cause the formation of atheromatous plagues or 
South American Journal of Academic Research

Special Edition May 2016

react with the cell membranes lipid and cause of peroxidation of polyunsaturated fatty acids and cause generation of further free radicals. So, the antioxidants are needed in the different compartments of the body such as the circulating system inside the cells and across the bloodbrain-barrier and central nervous system. Superoxide anion is a free radical generated by one electron transfer and plays an important role in the formation of other reactive oxygen species such as hydrogen peroxide, hydroxyl radical, or singlet oxygen in living system.

DPPH stable free radical method is an easy, rapid and sensitive way to survey the antioxidant activity of a specific compound or plant extracts (Koleva, 2002). When the odd electron becomes paired off in the presence of a free radical scavenger, the absorption reduces and the DPPH solution is decolorized as the colour changes from deep violet to light yellow. The degree of reduction in absorbance measurement indicated the free radical scavenging (antioxidant) activity of the extracts (Ayoola et al., 2008). The results of the DPPH free radical scavenging activity suggests that the leaf extract was capable of scavenging free radicals in dose dependant manner and thus may be able to prevent the initiation of free radicals mediated chain reactions by stabilizing reactive species. The DPPH free radical scavenging capacity showed significance results in S. cuspidata when compared to the standard/positive control (Rutin).This is supported by Wamtiga et al. (2006) who demonstrated that the six Acanthaceae members from Burkina Faso were the scavenging activity of all the samples on the DPPH radical was found to be strongly dependent on the extract concentration. It has been showed that the scavenging effects on the DPPH radical increase sharply with increasing concentration of the samples and standards to a certain extent (Motalleb et al., 2005).

$\mathrm{H}_{2} \mathrm{O}_{2}$ plays a signaling role in various adaptive processes and has an appropriate intracellular balance between $\mathrm{H}_{2} \mathrm{O}_{2}$ generation and scavenging exists in all cells. In plants, increased $\mathrm{H}_{2} \mathrm{O}_{2}$ level induces not only of defense genes, but also other resistance genes (Mittler et al., 2004). Hydrogen peroxide $\left(\mathrm{H}_{2} \mathrm{O}_{2}\right)$ acts as a signaling molecule, the second messenger, mediating the acquisition of tolerance to both biotic and abiotic stresses (Desikan et al., 2003).

Catalase breaks down hydrogen peroxide $\left(\mathrm{H}_{2} \mathrm{O}_{2}\right)$ to water and molecular oxygen while GPx reduces $\mathrm{H}_{2} \mathrm{O}_{2}$ to water at the cost of oxidation of reduced glutathione (GSH) (Jena and Chainy, 2011). Hydrogen peroxide, a weak oxidizing agent inactivates a few enzymes directly by oxidation of essential thiol (-SH) groups (Hazra et al., 2008). Hydrogen peroxide radical scavenging activity of the leaf extract of S.cuspidata was dose dependant and increased with concentration. Similar results were observed in the methanolic extract of Barleria montana leaves showed prominent $\mathrm{IC}_{50}$ value of $51 \mu \mathrm{g} / \mathrm{ml}$ in Hydrogen peroxide method (Shanaz et al., 2011).

Antioxidants inhibit interaction between metal and lipid through formation of insoluble metal complexes with ferrous ion (Hsu et al., 2003). The iron-chelating capacity test measures the ability of antioxidants to compete with ferrozine in chelating ferrous ion (Elmastas et al., 2006). Ferrozine can quantitatively form complexes with $\mathrm{Fe} 2+$. In the presence of samples possessing chelating activity, the formation of complexes is decreased. Therefore, measurement of the rate of color reduction helps to estimate the chelating activity of the samples (Chua et al., 2008). Metal chelating capacity of S. cuspidata increased with increase in concentration and revealed that has a less effective capacity for metal binding comparing to the positive control, suggesting that its action as an antioxidant may be related to its iron binding capacity.

The total antioxidant activity (TAC) is based on the reduction of Mo (VI) to Mo (V) by the extract and subsequent formation of green phosphate/Mo (V) complex at acid $\mathrm{pH}$. TAC of the phosphomolybdenum model evaluates both water-soluble and fat-soluble antioxidant capacity (total antioxidant capacity). The results obtained in TAC indicate concentration dependent total antioxidant capacity. it means that the leaf extract of S.cuspidata will have to contain as much quantity of antioxidants compounds as equivalents of rutin to effectively reduce the oxidant in the reaction matrix. Antioxidant capacity of rutin has been used as a reference 
standard from which plant extracts with potential antioxidant activity are compared (Aderogba et al., 2005)

In the present study the leaf extract of S.cuspidata showed dose dependent increase in antioxidant activity as the concentration increased and Ecobolium linneanum also supported the antioxidant activity and exhibited increasing trend with the increasing concentrations of plant extracts (Dipankar et al., 2012).

The Colorimetric microculture tetrazolium (MTT) assay is based on the capacity of Mitochondria succinate dehydrogenase enzymes in living cells to reduce the yellow water soluble substrate 3-(4, 5-dimethyl thiazol-2-yl)-2, 5-diphenyl tetrazolium bromide (MTT) into an insoluble, colored formazan product which is measured spectrophotometrically (Sanjay Patel et al., 2009). Since reduction of MTT can only occur in metabolically active cells, the level of activity is a measure of the viability of the cells. The cytotoxicity study was carried out for the leaf extract of $S$. cuspidata. The extract was screened for its cytotoxicity against Vero cell lines to determine the $\mathrm{IC}_{50}(50 \%$ growth inhibition) by MTT assay. The principal goal of this study was to determine if the leaf extract were cytotoxic at the dose level.

In the present study the leaf extract of $S$. cuspidata was assessed in Vero cell lines The 50 percent cytotoxic concentration $\left(\mathrm{CTC}_{50}\right)$ was determined by the standard MTT assay. The $\mathrm{IC}_{50}$ value of the alcoholic leaf extract was $190 \mu \mathrm{g} / \mathrm{ml}$. Some of the studies reported here below throw light on the cytotoxic potentials in comparison with other plants belonging to the same or different genera using similar experimental methods

The cytotoxic activity of $S$. cusia leaves along with five other plants has been investigated on cancer cell lines. The results showed that the dichloromethane and ethyl acetate extracts exhibited a marked cytotoxicity therefore supporting the ethno pharmacological uses of these species. (Nguyen et al., 2006)

Susi et al. (2007), studied and compared the cytotoxic effects of the extract of S. crispus on several kind of cancer cell lines. This was done in vitro using several kind of cancer cell lines and the mechanism was studied through the expression of cancer cell lines. S. crispus was found to be cytotoxic against human liver cancer cell (HepG2) and hormone dependent breast cancer cell lines (MCF-7). The cytotoxic effects of both plant extracts may be mediated by the down regulation of $c-m y c$ expression.

The cytotoxicity of standardized methanolic and aqueous extracts of S. crispus was analysed against a panel of cancer cell lines, namely, breast, colon, hepatocellular, lung and human breast ductal carcinoma and one normal colonic fibroblast cell line. The cell proliferation assay was performed using MTT assay. However only the higher concentrations of the extract demonstrated cytotoxicity against all cell lines except in breast cancer lines and the plant was concluded as a source of promising cytotoxic agents and angiogenesis inhibitors (Muslim et al., 2010).

Anticancer activity of the methanolic extracts of root, stem and leaves of Barlaria buxifolia Linn against Dalton's Lymphoma Ascites (DLA) cells using MTT assay was evaluated. Cytotoxicity was assayed by trypan blue dye exclusion method and MTT assay used to evaluate the reduction of viability of cell culture. Cell viability was inhibited to different extents by different concentrations of the extract. The data revealed that methanolic extract of roots of showed potent cytotoxic activity with a minimum inhibition $7 \%$ at a concentration of $10 \mu \mathrm{g} / \mathrm{ml}$ and maximum inhibition of $93 \%$ at a concentration of $200 \mu \mathrm{g} / \mathrm{ml}$ (Shivkumar, 2012).

Acanthus ilicifolius flower was cytotoxic towards lung fibroblast (L-929) cells in 72h MTT assay and the concentration required for $50 \%$ cell death was $18 \mu \mathrm{g} / \mathrm{ml}$, meanwhile the methanol extract of this plant was cytotoxic Hela and $\kappa B$ cell line (Muhamad Firdaus, 2013).

The roots of Justicea adhatoda were extracted with organic solvent and were screened for cytotoxic activity using brine shrimp lethality bioassay. A reputed cytotoxic agent vincristine sulphate was used as a positive control. From the results n-hexane, ethyl acetate and chloroform soluble fraction of methanolic crude extracts possess cytotoxic principles (with LC50 $1.129 \mu \mathrm{g} / \mathrm{ml}$, LC50 $1.402 \mu \mathrm{g} / \mathrm{ml}$ and LC50 $2.130 \mu \mathrm{g} / \mathrm{ml}$ respectively) comparison with positive control vincristine sulphate (with LC50 $0.563 \mu \mathrm{g} / \mathrm{ml}$ ) (Mumita Meskat ,2012). 
South American Journal of Academic Research

Special Edition May 2016

Initial screenings for cytotoxicity of ethanolic leaf and stem extracts of Ecbolium linneanum were performed on the HeLa cell line using the trypan blue assay. Among the plant extracts, ELLE induced over $80 \%$ death of Hela cells at a treatment concentration of $2 \mathrm{mg} / \mathrm{ml}(\mathrm{LC} 50-460 \mu \mathrm{g} / \mathrm{ml})$ and ELSE $(78 \%, \mathrm{LC} 50-490 \mu \mathrm{g} / \mathrm{ml})$. The cell viability data obtained in these extracts allow us to predict their potential not only because of the cystostatic effect, but in terms of potential for tumor reduction, (Dipankar, 2012).

\section{Conclusion}

The antioxidant capacities of the alcoholic leaf extracts of $S$. cuspidata was evaluated by using DPPH radical scavenging activity, hydrogen peroxide assay, metal chelating activity on ferrous ions and total antioxidant activity. DPPH radical scavenging activity of the leaf extract was significant and the IC50 value was calculated as $132(\mu \mathrm{g} / \mathrm{ml})$. Hydrogen peroxide assay was observed significance and the IC50 value was calculated as $185.4(\mu \mathrm{g} / \mathrm{ml})$. Metal chelating activity on ferrous ions was observed and the IC50 value was calculated as $225(\mu \mathrm{g} / \mathrm{ml})$. The total antioxidant capacity of the extract was calculated based on the formation of the phosphomolybdenum complex and the IC50 value was calculated as $90(\mu \mathrm{g} / \mathrm{ml})$. The in vitro cytotoxic activity of the alcoholic leaf extract was assessed in Vero cell lines. The 50 percent cytotoxic concentration (CTC50) was determined by the standard MTT assay which was significant. The CTC50 values of the alcoholic leaf extract was 190 $\mu \mathrm{g} / \mathrm{ml}$. The antioxidant, and cytotoxicity properties of the extract and will provide an insight into the medicinal properties and may inspire new biomedical applications for S. cuspidata. 